\title{
Studi Metode Diffusive Gradient In Thin Film dengan Binding Gel Titanium Dioksida-Chelex untuk Penyerapan Logam Besi(II) dan Fosfat Secara Simultan
}

\author{
Asep Saefumillah, Amalia Ekaputri Hidayat \\ Departemen Kimia, FMIPA, Universitas Indonesia, Kampus UI Depok, Depok 16424, Indonesia \\ Email :asep.saefumillah@gmail.com; amalia.ekaputri@gmail.com
}

Received: October 2017; Revised: November 2017; Accepted: November 2017; Available Online: November2017

\begin{abstract}
Abstrak
Tingginya konsentrasi fosfor sebagai fosfat ke dalam sistem akuatik mengakibatkan eutrofikasi yang berujung pada terjadinya algae blooming. Input fosfat dalam sistem akuatik ini dicurigai dipengaruhi oleh pelepasan fosfat yang terikat pada besi(III) hidroksida ketika tereduksi menjadi besi(II) di sedimen, sehingga diperlukan pengukuran fosfat dan besi(II) secara simultan. Teknik diffusive gradient in thin film (DGT) merupakan salah satu metode pengukuran in-situ yang dikembangkan untuk pengukuran fosfat dan logam. Teknik DGT diteliti menggunakan binding gel campuran TiO2-Chelex. Metode baru ini memperkenalkan penggunakan $\mathrm{TiO} 2$ hasil sintesis melalui metode sol-gel sebagai agen pengikat fosfat dan resin Chelex-100 sebagai agen pengikat logam $\mathrm{Fe}(\mathrm{II})$. DGT yang terdiri dari diffusive layer dan binding layer diuji kemampuannya dalam menyerap logam labil besi(II) dan fosfat secara terpisah, kemudian diuji homogenitasnya. DGT dengan binding gel TiO2-Chelex diuji pada sejumlah variasi waktu pengukuran, konsentrasi larutan, dan $\mathrm{pH}$. Hasil analisis menggunakan spektrofotometer AAS untuk logam besi dan spektrofotometer UV-Vis untuk fosfat menunjukkan bahwa waktu optimum untuk pengukuran DGT adalah 24 jam. DGT dengan binding gel TiO2-Chelex optimum mengukur fosfat pada larutan dengan $\mathrm{pH} 5.2$ dan $\mathrm{pH} 6$ dan optimum mengukur besi(II) pada $\mathrm{pH}$ netral (pH 7). DGT TiO2Chelex memiliki kapasitas pengukuran $5.86 \mathrm{mg} / \mathrm{L}$ untuk fosfat dan $53.41 \mathrm{mg} / \mathrm{L}$ untuk logam besi(II). Sehingga dapat disimpulkan bahwa, binding gel campuran TiO2-Chelex yang telah dibuat dalam sistem DGT dapat menyerap logam $\mathrm{Fe}$ (II) dan fosfat secara simultan dengan baik.
\end{abstract}

Kata kunci: Diffusive gel, fosfat, besi(II), metode DGT, $\mathrm{TiO}_{2}$

\begin{abstract}
The high phosphorus as phosphate input into aquatic systems causes eutrophication which leads to the occurrence of algae blooming. Phosphate input in aquatic systems is influenced by the release of suspected phosphate bound to iron(III) when reduced to iron(II) in the sediment. Diffusive gradients in thin films (DGT) technique is one of the in-situ measurement methods developed for the measurement of phosphate and metals. DGT technique was studied using gel bindings mixture of TiO2-Chelex. This new method introduces the use synthesis of $\mathrm{TiO} 2$ via sol-gel method and resin Chelex-100 as phosphate and iron(II) binding agents, respectively. DGT composed of diffusive and binding layer was tested for their ability to absorb iron(II) and phosphate separately, and homogeneity. DGT with bindings TiO2-Chelex gel was tested at various measurement time, solution concentration, and $\mathrm{pH}$. The results of the analysis using AAS for iron and UV - Vis spectrophotometer for phosphate showed that the optimum time for DGT measurement is 24 hours. Optimum measurement of DGT with bindings gel TiO2-Chelex was reached at $\mathrm{pH}$ around $\mathrm{pH} 5.2$ and 6 for phosphate, and neutral ( $\mathrm{pH} 7$ ) for iron(II). TiO2-Chelex DGT measurement capacity was $5.86 \mathrm{mg} / \mathrm{L}$ and $53.41 \mathrm{mg} / \mathrm{L}$ for phosphate and iron (II), respectively. In conclusion, the $\mathrm{TiO}_{2}$-Chelex mixed binding gel that was made can absorb iron (II) and phosphate simultaneously.
\end{abstract}

Keywords: Diffusive gel, phosphate, iron(II), DGT technique, $\mathrm{TiO}_{2}$.

DOI: http://dx.doi.org/10.15408/jkv.v3i2.6078 


\section{PENDAHULUAN}

Fosfor (P) merupakan nutrien pembatas pada produktivitas biologis dalam ekosistem akuatik. Fosfor berada di perairan dalam bentuk ortofosfat $\left(\mathrm{H}_{2} \mathrm{PO}_{4}{ }^{-}\right)$yang dianggap sebagai bentuk yang paling sederhana yang mampu diserap secara biologis oleh biota akuatik (Teasdale et al., 2011). Pelepasan fosfor dari sedimen dapat berkontribusi besar dalam peningkatan jumlah fosfor di perairan, yang dapat berakibat pada pertumbuhan alga. Mekanisme dibalik pelepasan fosfor dari sedimen dapat dijelaskan oleh konsep tradisional yang diusulkan Mortimer, yaitu pengaruh reaksi redoks pada pelepasan fosfor ke permukaan sedimen perairan berdasarkan interaksinya terhadap siklus besi. Mortimer menjelaskan bahwa redoks dari besi mengendalikan pelepasan fosfor di sedimen, dimana $\mathrm{P}$ diikat oleh $\mathrm{Fe}(\mathrm{III})$ oksihidroksida dan dilepaskan ketika $\mathrm{Fe}$ (III) tereduksi menjadi Fe(II) pada keadaan anoksik (miskin oksigen).

Pengamatan terhadap fenomena tersebut dapat memberikan bukti secara langsung yang mendukung hipotesis bahwa pelepasan fosfor sebenarnya dikendalikan oleh siklus besi di sedimen. Namun, penelitian-penelitian yang sudah dilakukan selama ini belum dapat dikatakan valid karena analisis yang dilakukan secara ex situ. Oleh sebab itu dibutuhkan teknik analisis secara in situ, yaitu penyerapan dilingkungan aslinya.

Pada tahun 1993, Bill Davison dan Hao Zhang menemukan metode analisis dengan mengunakan DGT (Diffusive Gradient in Thin Film). Teknik DGT ditetapkan sebagai teknik in situ yang sangat baik dan metode passive sampling yang sesuai untuk mengukur spesi labil yang terakumulasi di lingkungan akuatik. Teknik DGT dikembangkan untuk pengukuran in situ terhadap spesi fosfor dan logam labil yang reaktif. Dengan teknik DGT, konsentrasi rata-rata solut yang terukur selama waktu tertentu dapat diketahui, kontaminasi sampel dapat dikurangi, dan memungkinkan untuk prekonsentrasi solut tanpa merusak sampel. Spesifisitas dari teknik DGT terletak pada agen pengikat yang spesifik terhadap suatu solut tertentu. Berbagai senyawa pengikat pada binding gel telah digunakan, antara lain untuk monitoring ortofosfat menggunakan $\mathrm{TiO}_{2}$ (Zhang et al., 1998) dan kation logam labil menggunakan resin Chelex-100 gel (Zhang dan Davison, 1995).
Prinsip yang diterapkan oleh metode ini adalah spesi analit berdifusi melalui lapisan poliakrilamida (lapisan difusi) yang diketahui ketebalannya, kemudian diikat oleh suatu adsorben, dan dielusi untuk diketahui konsentrasinya. Konsentrasi spesi analit yang diikat oleh DGT dianggap sama dengan konsentrasi yang mungkin berdifusi ke biota akuatik. Dengan menggunakan nilai koefisien difusi untuk menentukan spesi analit yang terikat, maka DGT dapat digunakan untuk mengukur fosfat atau logam labil dalam larutan secara akurat tanpa kalibrasi.

Pengukuran spesi Fe(II) dan P sebagai ortofosfat secara simultan dapat dilakukan dengan memodifikasi binding layer dari DGT tersebut agar dapat mengikat $\mathrm{Fe}(\mathrm{II})$ dan fosfat secara simultan. Binding gel dengan binding agent tunggal sudah pernah dikembangkan untuk pengukuran $\mathrm{Fe}(\mathrm{II})$ atau fosfat. Inna (Husna, 2012) telah melakukan pengembangan metode DGT dengan membandingkan binding gel $\mathrm{TiO}_{2}$ dengan binding gel ferrihidrit untuk pengukuran fosfat di lingkungan perairan. Pada penelitian sebelumnya Zhang et al., melakukan spesiasi logam dengan metode DGT resin gel dan spesiasi fosfat dengan metode DGT $\mathrm{TiO}_{2}$ dan DGT ferihidrit. Selain itu, sudah pernah dilakukan pengembangan DGT dengan binding gel campuran ferihidrit-Chelex 100 untuk spesiasi kation dan anion secara simultan, namun penggunaan ferihidrit menunjukkan kapasitas DGT yang rendah pada pengukuran $\mathrm{P}$ (Mason, 1993). Xu et al., (2013) juga melakukan penelitian pada tahun 2012 mengenai pengembangan DGT dengan binding gel campuran $\mathrm{ZrO}-$ Chelex untuk spesiasi Fe(II) dan $\mathrm{P}$ terlarut secara simultan di sedimen, namun dibutuhkan penelitian lebih lanjut agar dapat membuktikan fenomena teori yang diajukan oleh Mortimer.

Oleh karena itu, diperlukan suatu metode pengukuran kadar fosfat di lingkungan. Berbagai riset telah dilakukan untuk mengukur kadar fosfat dalam sampel akuatik. Metode yang dapat dilakukan untuk mengukur kadar fosfat, salah satunya adalah dengan meode DGT (Diffusive Gradient in Thin Film). Metode DGT ini merupakan metode in situ yang sangat baik dan mudah untuk mengukur spesi labil di lingkungan akuatik. Prinsip dasar dari metode ini pengikatan spesi analit pada suatu binding gel atau adsorben setelah berdifusi melalui suatu hidrogel kemudian dielusikan dengan suatu asam untuk 
mengetahui konsentrasinya. Pada teknik DGT, konsentrasi rata-rata solut yang terukur selama waktu tertentu dapat diketahui, kontaminasi sampel dapat dikurangi, dan memungkinkan melakukan prekonsentrasi tanpa merusak sampel. Konsentrasi spesi analit yang diikat oleh binding gel pada DGT dapat dianggap sama dengan konsentrasi yang mungkin berdifusi dari air ke biota akuatik sehingga metode ini dapat digunakan untuk memprediksi bioavaibilitas suatu logam labil, sulfat, dan fosfat (Zhang dan Davison, 1995). Pengukuran spesi $\mathrm{Fe}(\mathrm{II})$ dan $\mathrm{P}$ sebagai ortofosfat secara simultan dapat dilakukan dengan memodifikasi binding layer dari DGT tersebut agar dapat mengikat Fe(II) dan fosfat secara simultan.

Pada penelitian ini, penulis akan menggunakan teknik DGT untuk pengukuran $\mathrm{Fe}$ (II) dan fosfat dengan binding gel campuran TiO2-Chelex 100. Selain itu penulis juga akan menentukan kemampuan DGT $\neg$ TiO2-Chelex 100 gel jika dibandingkan dengan metode DGT $\neg$ dengan binding gel tunggal $\mathrm{TiO} 2$ dan resin Chelex 100 gel sebagai metode awal yang ditetapkan untuk pengukuran $\mathrm{Fe}$ (II) dan fosfat dengan perangkat DGT.

\section{METODE PENELITIAN.}

\section{Prosedur Penelitian}

Pada penelitian ini, dilakukan sintesis $\mathrm{TiO}_{2}$ terlebih dahulu menggunakan metode solgel. Kemudian dilakukan sistesis diffusive gel dan binding gel $\mathrm{TiO}_{2}$-Chelex menggunakan $\mathrm{TiO}_{2}$ hasil sintesis. $\mathrm{TiO}_{2}$ berfungsi sebagai binding agent fosfat dan resin Chelex-100 berfungsi sebagai binding agent $\mathrm{Fe}(\mathrm{II})$. Diffusive gel dan binding gel disusun pada perangkat DGT sehingga dapat dikontakkan pada larutan uji. Untuk mengetahui kondisi optimum dan pengaruh kondisi dari proses pengukuran fosfat dan $\mathrm{Fe}(\mathrm{II})$ secara simultan menggunakan teknik DGT ini, maka dilakukan beberapa uji yaitu uji homogenitas, uji optimasi waktu kontak, uji pengaruh variasi $\mathrm{pH}$, dan uji pengaruh konsentrasi. Bagan Kerja. Seperti dapat dilihat pada gambar 1 .

\section{Analisis Sampel}

Pengukuran konsentrasi $\mathrm{P}$ menggunakan Spektrofotometer UV-Visible pada $\lambda=720 \mathrm{~nm}$. Nilai absorbansi diamati berdasarkan terbentuknya kompleks biru fosfomolibdenum. Pengukuran konsentrasi $\mathrm{Fe}$ menggunakan Atomic Absorption Spectrofotometer. Diffusive gel dan binding gel dikarakterisasi menggunakan FTIR dan SEM-EDS.

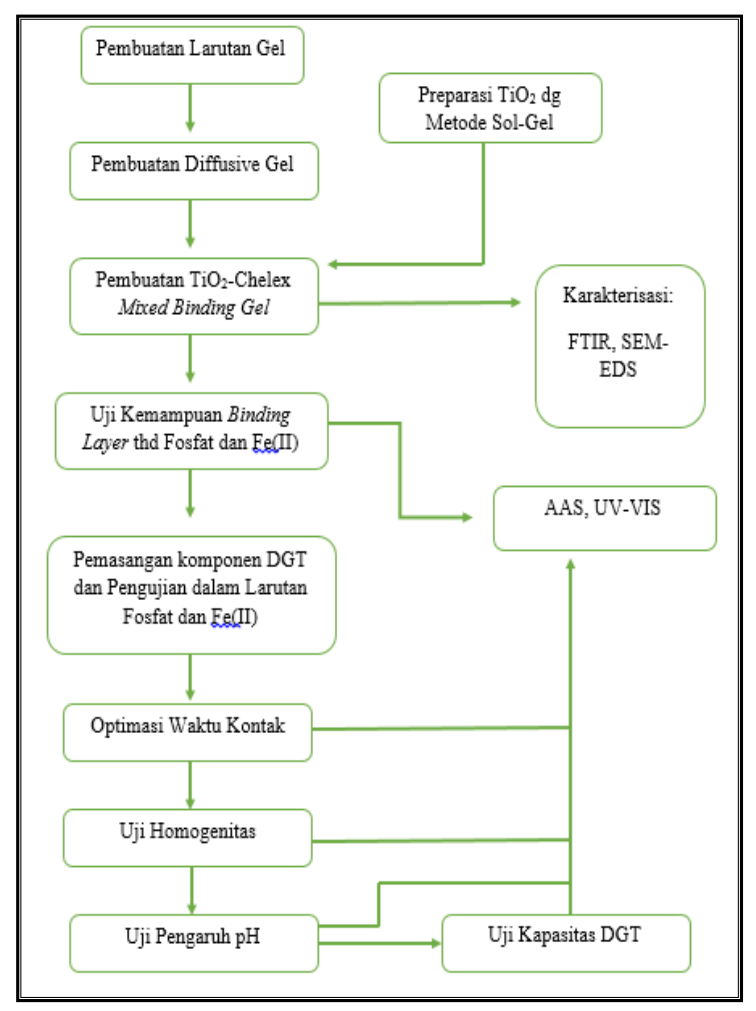

Gambar 1. Bagan kerja penelitian

\section{HASIL DAN PEMBAHASAN}

\section{Sintesis $\mathrm{TiO}_{2}$ Metode Sol-Gel}

Sintesis titanium dioksida dilakukan dengan mereaksikan TTIP (titanium tetraisopropoksida), DEA (dietanol amin), etanol, dan PEG 1000 (polietilen glikol dengan berat molekul 1000). Sintesis dimulai dengan mencampurkan etanol dengan DEA dan TTIP. Etanol berfungsi sebagai pelarut, DEA sebagai complexing agent dan TTIP sebagai prekursor titania. Selanjutnya diaduk menggunakan stirrer selama dua jam agar campuran homogen. DEA sebagai complexing agent akan mengontrol laju hidrolisis dan kondensasi dari TTIP yang berlangsung cepat dengan tujuan untuk memperoleh besar pori sesuai dengan yang diinginkan.

Setelah pengadukan selama dua jam, selanjutnya ditambahkan etanol:air (4.5:0.1) untuk memulai hidrolisis dan PEG 1000 sebagai template yang mempengaruhi pembentukan struktur pori $\mathrm{TiO}_{2}$. Semakin banyak jumlah PEG serta semakin besar berat molekulnya maka ukuran pori yang terbentuk juga semakin besar (Teasdale et al., 2010). 
Kemudian diaduk lagi dengan stirrer selama dua jam untuk mempercepat reaksi.

Setelah total empat jam reaksi, maka akan dihasilkan larutan berwarna bening kekuningan. Larutan ini kemudian didiamkan selama 4-7 hari hingga berubah bentuk menjadi gel dan pengeringan untuk menghilangkan air dari gel. Selanjutnya dilakukan kalsinasi untuk mengubah sifat-sifat fisik/kimia yaitu menghilangkan template PEG yang ada dalam rongga $\mathrm{TiO}_{2}$ sekaligus mengubah fasa amorf menjadi fasa anatase menghasilkan kristal $\mathrm{TiO}_{2}$. Proses kalsinasi dilakukan dalam kurun waktu 4-8 jam. Kalsinasi terhadap gel $\mathrm{TiO}_{2}$ yang awalnya berwarna kuning dilakukan hingga diperoleh kristal berwarna putih dengan butiran mengkilap yang kasar.

\section{Pembuatan dan Pemasangan Perangkat DGT}

Pembuatan diffusive gel dan binding gel harus diawali dengan pembuatan larutan gel terlebih dahulu. Untuk membuat satu cetakan diffusive gel maupun binding gel dibutuhkan larutan gel sebanyak $5 \mathrm{~mL}$. Prosedur pembuatan larutan gel ini mengikuti prosedur dari Hao Zhang (1998), dimana larutan gel terdiri dari cross-linker, air, dan akrilamida. Cross-linker yang digunakan merupakan hasil paten dari DGT Research dengan konsentrasi $2 \%$, namun pada pembuatan larutan gel, crosslinker yang dibutuhkan adalah dengan konsentrasi $0.3 \%$, maka dari itu dibutuhkan penambahan air untuk menurunkan konsentrasi dari cross-linker. Setelah larutan gel tercampur homogen maka dilakukan penambahan inisiator. Inisiator untuk reaksi ini adalah larutan ammonium persulfat $10 \%$. Sesuai seperti yang dikatakan oleh Hao Zhang (2005). bahwa konsentrasi ammonium persulfat yang tepat digunakan adalah sebesar $10 \%$.Setelah penambahan inisiator, dilakukan penambahan katalis. Katalis yang digunakan untuk reaksi ini yaitu TEMED (N,N,N'N'Tetrametiletilendiamin). Pengadukan setelah ditambahkan TEMED kurang lebih 15-20 detik. Dengan pengadukan akan menyebabkan tumbukan dapat mempercepat polimerisasi.

Larutan diffusive gel yang telah dibuat dengan segera dimasukkan dalam cetakan dengan hati-hati sampai cetakan terisi gel secara menyeluruh, dan tidak terbentuk gelembung. Jika terbentuk gelembung pemipetan dihentikan sementara hingga gelembung hilang agar semua bagian sama.
Pemindahan ke cetakan harus segera dilakukan setelah pengadukan karena polimerisasi berlangsung sangat cepat. Apabila terlalu lama pengadukan dan tidak segera dimasukan ke dalam cetakan maka campuran akan mengental sehingga tidak dapat lagi di pipet ke dalam cetakan. Apabila sudah terjadi hal demikian, maka campuran sudah tidak dapat digunakan untuk pembuatan diffusive gel.

\section{Karakterisasi gel dengan SEM-EDS}

Karakterisasi gel menggunakan alat Scanning Electron Microscopy-Energy Dispersive Spectroscopy (SEM-EDS) bertujuan untuk melihat penampakan morfologi dari diffusive gel dan mixed binding gel, serta komposisi unsur-unsur penyusunnya. Permukaan diffusive gel dan binding gel $\mathrm{TiO}_{2}$ dapat dilihat pada Gambar 2. Untuk hasil EDS yang menunjukkan karakter dari spesimen yang digunakan seperti yang terlihat pada Gambar 3 .

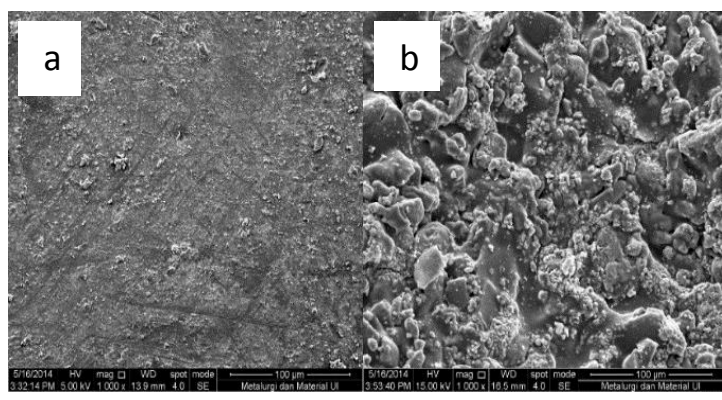

Gambar 2. Permukaan diffusive gel (a), permukaan binding gel (b)

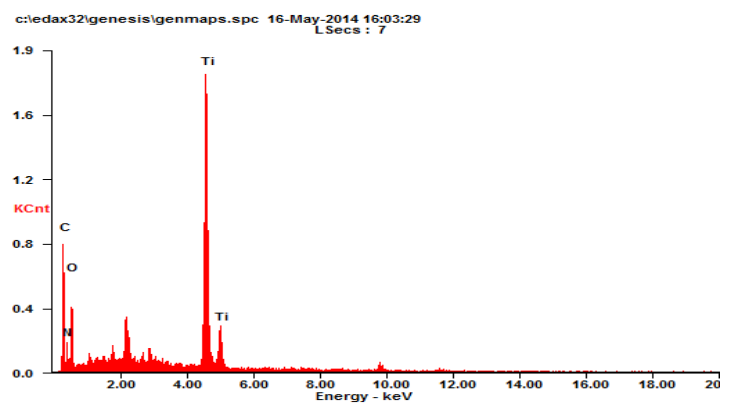

Gambar 3. Grafik analisis kualitatif SEM-EDS binding gel campuran

Dari Gambar 3 diketahui bahwa pada binding gel campuran ditemukan unsur $\mathrm{C}$ yang dipastikan berasal dari poliakrilamida, $\mathrm{O}$ yang berasal dari poliakrilamida, $\mathrm{TiO}_{2}$, dan Chelex100, Ti dari $\mathrm{TiO}_{2}$ serta $\mathrm{N}$ dari Chelex-100. 


\section{Karakterisasi gel dengan FTIR}

Untuk mengetahui gugus fungsi yang terdapat pada diffusive gel dan binding gel, dilakukan karakterisasi FTIR.

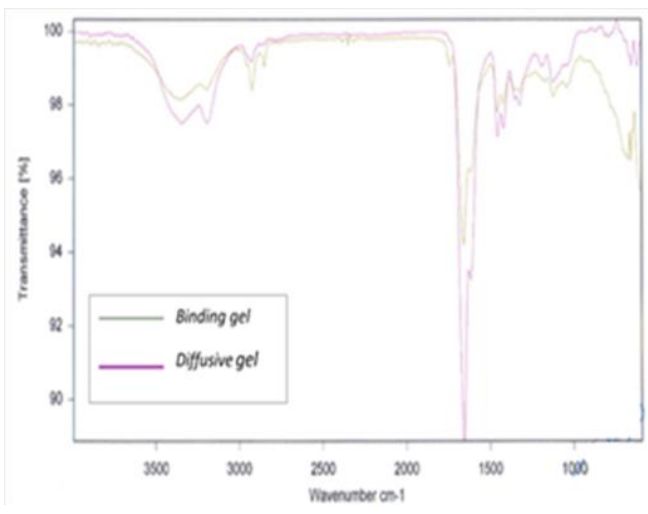

Gambar 4. Spektrum FTIR binding gel dan diffusive gel

Pada Gambar 4, bilangan gelombang yang diperoleh dari hasil FTIR diffusive gel antara lain pada sekitar $3200 \mathrm{~cm}^{-1}$ menunjukkan adanya amida primer. Terlihatnya gugus amida karena gel terbentuk merupakan poliakrilamida yang mengandung gugus amida. Terdapat puncak pada bilangan gelombng $2927 \mathrm{~cm}^{-1}$ menunjukkan adanya uluran $\mathrm{C}-\mathrm{H}$. Bilangan gelombang ini berasal dari rantai $\mathrm{C}-\mathrm{H}$ pada polimer. Bilangan gelombang $1656 \mathrm{~cm}^{-1}$ menunjukkan adanya uluran $\mathrm{C}=\mathrm{O}$ yang berasal dari poliakrilamida. Dari spektrum tersebut juga tidak ditemukan adanya serapan untuk $\mathrm{C}=\mathrm{C}$ yang artinya polimerisasi telah berhasil dilakukan.

Untuk spektra FT-IR yang dihasilkan dari binding gel campuran tidak jauh berbeda dengan spektra diffusive gel. Hal ini dikarenakan baik diffusive gel maupun binding gel campuran terbuat dari poliakrilamida. Pada daerah sekitar $1700 \mathrm{~cm}^{-1}$ menunjukkan adanya $-\mathrm{COO}^{-}$yang berasal dari gugus iminodiasetat dari resin Chelex dan terdapat puncak pada daerah sekitar $600 \mathrm{~cm}^{-1}$ yang menunjukkan gugus Ti-O.

\section{Uji Kemampuan Mixed Binding Gel $\mathrm{TiO}_{2^{-}}$ Chelex pada Larutan Fosfat}

Pengujian kemampuan binding gel dilakukan bertujuan untuk menguji apakah mixed binding gel yang telah dibuat benarbenar dapat menyerap logam dan fosfat, serta mengetahui apakah selama 8 jam massa logam yang terserap resin masih linear, atau hanya dengan waktu kurang dari 8 jam massa resin yang terserap sudah konstan. Percobaan ini dilakukan pada masing-masing larutan logam $\mathrm{Fe}(\mathrm{II})$ dan fosfat $\left(\mathrm{P}^{-} \mathrm{PO}_{4}{ }^{2-}\right)$ secara terpisah dengan konsentrasi $5 \mathrm{mg} / \mathrm{L}$. Binding gel yang digunakan untuk percobaan ini tidak digunakan ukuran seperti DGT dengan diameter $2.5 \mathrm{~cm}$, tetapi binding gel yang digunakan dipotong dengan ukuran $1 \times 1$. Binding gel yang telah dipotong direndam dalam fosfat selama 1, 2, 3, 4, 5, 6, 7, dan 8 jam. Namun untuk larutan logam, sebelumnya dilakukan purging dengan gas $\mathrm{N}_{2}$ selama beberapa menit untuk meghilangkan sisa oksigen dalam larutan. Pengontakan binding gel dengan larutan logam, dilakukan dalam keadaan diisolasi dengan gas $\mathrm{N}_{2}$.

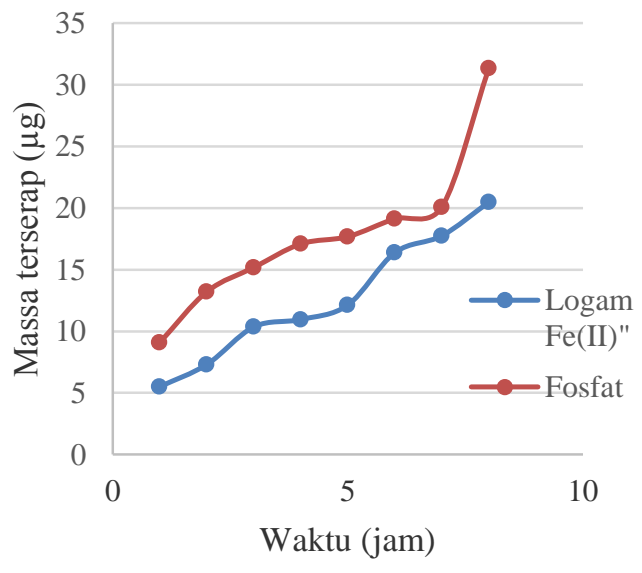

Gambar 5. Grafik hubungan waktu dengan massa logam dan fosfat terserap

Sesuai data pada Gambar 5, terlihat dalam waktu 7 jam sudah dihasilkan effisiensi lebih dari $50 \%$, yaitu $50.02 \%$. Untuk massa logam besi dalam resin dari 1 sampai 8 jam, terlihat semakin meningkat dengan pertambahan waktu, walau konstan pada waktu tertentu. Dari hasil tersebut dapat disimpulkan bahwa binding gel campuran $\mathrm{TiO}_{2}$-Chelex dapat digunakan untuk pengukuran logam Fe(II). Dari hasil tersebut dapat dilihat bahwa jumlah fosfat yang terikat setiap penambahan waktu perendaman cenderung semakin meningkat, walaupun konstan pada waktu tertentu seperti pada pengukuran logam $\mathrm{Fe}(\mathrm{II})$. Namun hal tersebut tetap membuktikan bahwa binding gel campuran $\mathrm{TiO}_{2}$-Chelex dapat digunakan untuk pengukuran fosfat. 


\section{Uji Homogenitas DGT $\mathrm{TiO}_{2}$-Chelex Binding Gel}

Uji homogenitas dilakukan untuk mengetahui apakah binding gel campuran yang telah dibuat untuk pengujian homogen atau tidak. Uji homogenitas ini dilakukan dengan campuran larutan standar $\mathrm{Fe}^{2+}$ dan fosfat (P$\mathrm{PO}_{4}{ }^{2-}$ ) dengan masing-masing konsentrasi 4 $\mathrm{mg} / \mathrm{L}$ sebanyak $1000 \mathrm{ml}$ selama 24 jam deployment dengan tiga kali pengulangan dalam keadaan dialiri gas $\mathrm{N}_{2}$ dan diaduk dengan pengaduk magnetik. Dengan empat DGT yang berbeda diuji pada larutan dengan konsentrasi dan waktu deployment yang sama.

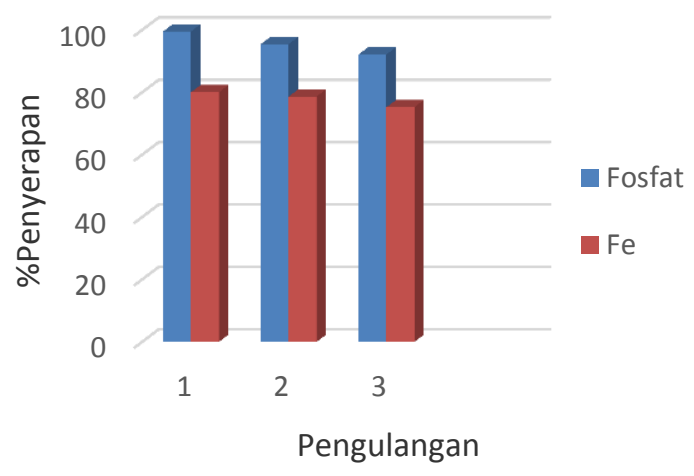

Gambar 6. Grafik uji homogenitas binding gel campuran terhadap \%penyerapan

Dari data pada Gambar 6 di atas dapat terlihat dengan pengulangan binding gel campuran sebanyak tiga kali didapatkan massa dalam resin yang tidak jauh berbeda. Berbedanya konsentrasi terukur oleh DGT $\left(\mathrm{C}_{\mathrm{DGT}}\right)$ dari keempat DGT dikarenakan konsentrasi larutan standar yang berbeda. Namun, $C_{\text {DGT }}$ yang diperoleh cukup dekat. Dengan melihat hasil tersebut dapat disimpulkan bahwa binding gel campuran yang telah dibuat cukup homogen. Dari perhitungan didapatkan standar deviasi 0.144 untuk fosfat dan 0.142 untuk logam besi, serta diperoleh \% RSD sebesar $3.13 \%$ untuk fosfat dan $3.47 \%$ untuk logam besi.

\section{Pegaruh Konsentrasi Larutan Terhadap Konsentrasi Terukur DGT}

Pengujian variasi konsentrasi ini dilakukan untuk mengetahui hasil pengukuran DGT pada berbagai konsentrasi analit dan dapat diketahui seberapa besar massa maksimum logam yang dapat diadsorb binding gel. Sesuai Gambar 7 dan 8 variasi ini dilakukan dengan konsentrasi $\mathrm{Fe}(\mathrm{II})$ dan fosfat $\left(\mathrm{P}_{-} \mathrm{PO}_{4}{ }^{2-}\right)$ 1, 5, 10, 25, 50 dan $100 \mathrm{mg} / \mathrm{L}$ dengan waktu deployment 24 jam. Untuk dapat melihat apakah keberadaan resin Chelex atau $\mathrm{TiO}_{2}$ dapat mempengaruhi pengikatan logam atau fosfat satu sama lain, maka dilakukan pula uji variasi konsentrasi ini pada binding gel tunggal $\mathrm{TiO}_{2}$ dan Chelex-100. Hasil yang diperoleh dari ketiga jenis binding gel tersebut kemudian dibandingkan agar dapat terlihat apakah hasil pengukuran binding gel campuran $\mathrm{TiO}_{2}$-Chelex terhadap spesi logam dan fosfat menyerupai hasil jika dilakukan pengukuran dengan binding gel tunggal $\mathrm{TiO}_{2}$ dan Chelex-100.

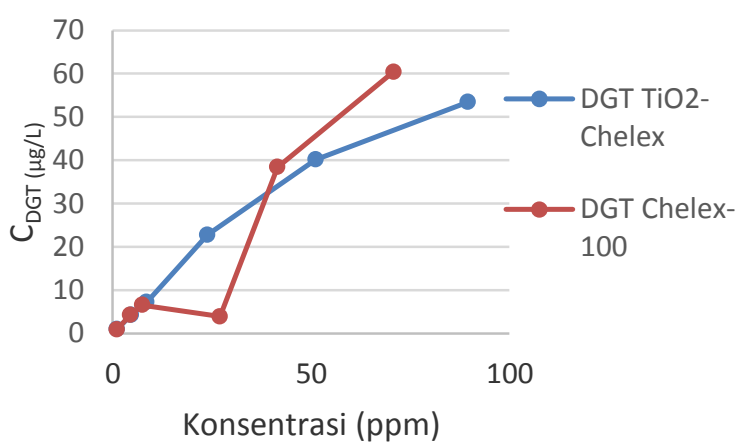

Gambar 7. Grafik hubungan konsentrasi DGT terhadap konsentrasi Besi antara DGT Chelex-100 dengan DGT $\mathrm{TiO}_{2^{-}}$ Chelex

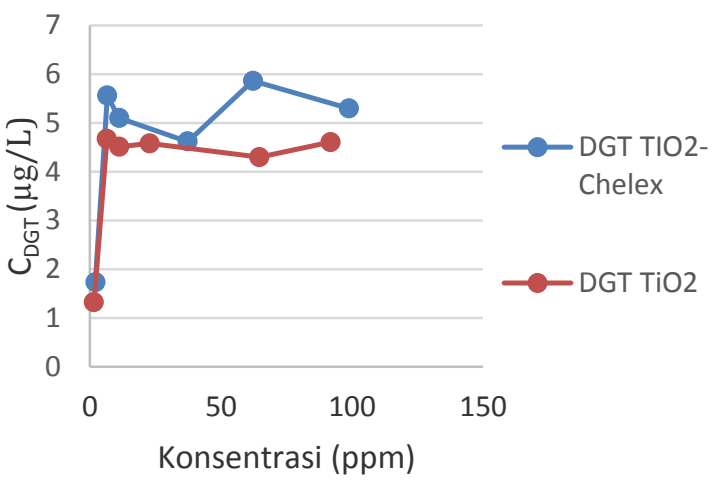

Gambar 8. Grafik hubungan konsentrasi DGT terhadap konsentrasi fosfat antara DGT $\mathrm{TiO}_{2}$ dengan DGT $\mathrm{TiO}_{2}$-Chelex

Dari Gambar 7 dan Gambar 8 dapat disimpulkan bahwa keberadaan $\mathrm{TiO}_{2}$ atau Chelex-100 pada binding gel campuran tidak saling mengganggu untuk pengukuran fosfat maupun $\mathrm{Fe}(\mathrm{II})$ secara simultan, karena hasil dari variasi ini tidak berbeda jauh dengan hasil dari vaeriasi konsentrasi dengan binding gel tunggal $\mathrm{TiO}_{2}$ maupun Chelex 100 gel. Oleh 
karena itu, dapat disimpulkan bahwa DGT $\mathrm{TiO}_{2}$-Chelex 100 efektif dalam pengukuran fosfat dan Fe(II) secara simultan.

\section{Pengaruh pH Larutan terhadap Pengukuran DGT}

Pengujian variasi $\mathrm{pH}$ ini bertujuan untuk mengetahui pengaruh $\mathrm{pH}$ terhadap pengukuran $\mathrm{Fe}$ (II) dan fosfat, serta untuk mengetahui range $\mathrm{pH}$ yang dapat ditolerir dalam pengujian fosfat dan $\mathrm{Fe}(\mathrm{II})$ dengan DGT $\mathrm{TiO}_{2}$-Chelex. Pengujian ini dilakukan pada $\mathrm{pH} 2.9 ; 4.3 ; 6.13$; 7.38; dan 8,21. Variasi $\mathrm{pH}$ dilakukan dengan cara menambahkan $\mathrm{HNO}_{3}$ untuk membuat $\mathrm{pH}$ asam maupun menambahkan $\mathrm{NaOH}$ untuk membuat $\mathrm{pH}$ basa.

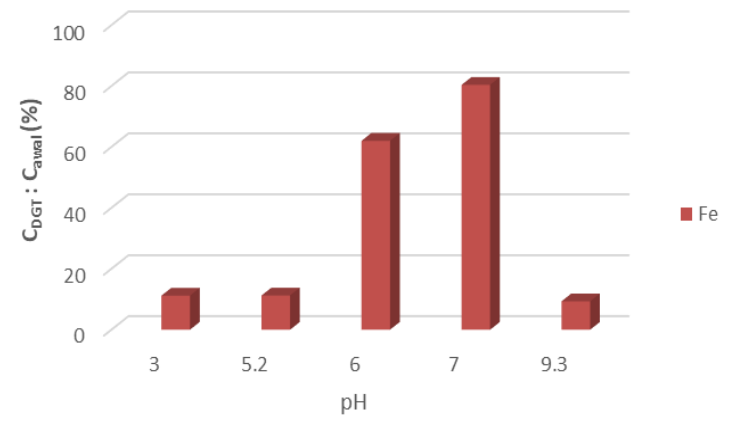

Gambar 9. Grafik hubungan $\mathrm{pH}$ dan $\mathrm{C}_{\mathrm{DGT}}: \mathrm{C}_{\mathrm{awal}}$ logam besi

Dari Gambar 9. didapatkan konsentrasi yang terukur oleh DGT pada $\mathrm{pH} 6$ yaitu 3,14 $\mathrm{mg} / \mathrm{L}$, yang merupakan $\mathrm{pH}$ optimum, sedangkan pada $\mathrm{pH} 7$ diperoleh $\mathrm{C}_{\text {DGT }}$ sebesar $2.59 \mathrm{mg} / \mathrm{L}$. Pada $\mathrm{pH} 3$; 5.2; dan 9.3 diperoleh $\mathrm{C}_{\text {DGT }}$ yang lebih kecil yaitu $0.58 \mathrm{mg} / \mathrm{L} ; 0.57$ $\mathrm{mg} / \mathrm{L}$; dan yang terkecil $0.27 \mathrm{mg} / \mathrm{L}$. Hal ini kemungkinan disebabkan bahwa adanya sebagian ion $\mathrm{Fe}^{2+}$ yang sudah teroksidasi dan membentuk endapan $\mathrm{Fe}(\mathrm{OH})_{3}$. Fenomena ini disebakan adanya ion-ion $\mathrm{OH}^{-}$yang berasal dari larutan $\mathrm{NaOH}$ yang ditambahkan ketika mengatur $\mathrm{pH}$ larutan menjadi lebih basa. Ionion $\mathrm{OH}^{-}$ini bereaksi dengan ion $\mathrm{Fe}^{2+}$ dan mengoksidasi $\mathrm{Fe}^{2+}$ menjadi $\mathrm{Fe}^{3+}$. Selain itu, adanya $\mathrm{OH}^{-}$menyebabkan sebagian $\mathrm{Fe}^{3+}$ membentuk endapan $\mathrm{Fe}(\mathrm{OH})_{3}$. Dapat dilihat dari adanya padatan halus berwarna kekuningan yang terbentuk. Pengendapan ini terjadi karena nilai ksp $\mathrm{Fe}(\mathrm{OH})_{3}$ yaitu 6.3 x 1038. Pada pH 7-9, nilai hasil kali kelarutan dari ion-ionnya lebih besar dari harga Ksp, maka terbentuk endapan $\mathrm{Fe}(\mathrm{OH})_{3}$. Hal ini menyebabkan ion $\mathrm{Fe}^{2+}$ yang dapat berdifusi ke dalam resin menurun akibat ukuran $\mathrm{Fe}(\mathrm{OH})_{3}$ yang lebih besar dibandingkan dengan ukuran pori-pori membran, sehingga tidak dapat berdifusi melewati diffusive layer dan sampai ke sisi pengikat.

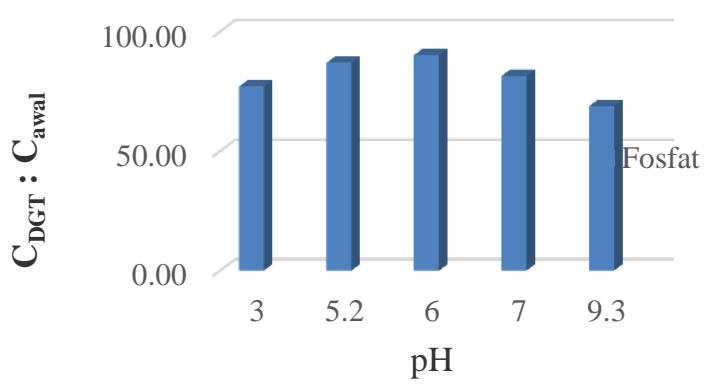

Gambar 10. Grafik hubungan $\mathrm{pH}$ dan $\mathrm{C}_{\mathrm{DGT}}: \mathrm{C}_{\mathrm{awal}}$ fosfat

Berdasarkan Gambar 10, dapat dilihat pada fungsi $\mathrm{pH}$ tertentu fraksi dari spesi fosfat akan berubah menjadi fraksi tertentu. Sebagai contoh, pada $\mathrm{pH}$ kurang dari 2 fraksi fosfat yang terbentuk dilingkungan adalah asam ortofosfat dan sebagian kecil adalah ortofosfat, pada $\mathrm{pH} 3$ fraksi yang terbentuk dilingkungan adalah sebagian besar ortofosfat dan ada sebagian kecil dalam bentuk asam ortofosfat, dan pada pH 5 seluruh spesi fosfat berada pada fraksi ortofosfat

\section{SIMPULAN}

Berdasarkan percobaan yang telah dilakukan dan hasil-hasil analisis yang didapatkan, maka disimpulkan bahwa: Binding gel campuran $\mathrm{TiO}_{2}$-Chelex yang telah dibuat dapat menyerap logam $\mathrm{Fe}$ (II) dan fosfat secara simultan. $\mathrm{TiO}_{2}$ dan resin Chelex dalam Binding gel tersebar secara homogen. Waktu untuk mendapatkan konsentrasi DGT dengan binding gel campuran $\mathrm{TiO}_{2}$-Chelex yang mendekati konsentrasi larutan sebenarnya adalah 24 jam. DGT dengan binding gel campuran $\mathrm{TiO}_{2^{-}}$ Chelex 100 dapat mengukur larutan uji $\mathrm{Fe}$ (II) sampai $53.41 \mathrm{mg} / \mathrm{L}$ sedangkan kapasitas maksimumnya terhadap fosfat $5.86 \mathrm{mg} / \mathrm{L}$. Keberadaan $\mathrm{TiO}_{2}$ dan Chelex-100 pada binding gel campuran tidak saling mengganggu pengukuran fosfat maupun $\mathrm{Fe}$ (II) secara simultan. DGT dengan menggunakan binding gel campuran, paling efektif digunakan pada larutan dengan $\mathrm{pH} 2.9$ untuk pengukuran fosfat dan logam Fe(II) secara simultan. 
Penelitian mengenai pengembangan teknik DGT dengan binding gel $\mathrm{TiO} 2$ untuk pengukuran fosfat ini belum sempurna. Untuk peninjauan yang lebih baik, perlu dilakukan aplikasi secara langsung ke lingkungan perairan dan sedimen. Selain itu, dapat dilakukan uji adsorpsi fosfat dan logam $\mathrm{Fe}$ (II) dengan adanya interferensi senyawa fosfat dan logam yang lain, seperti phytic acid (inositol heksakisfosfat), logam $\mathrm{Al}, \mathrm{Cu}$, dan $\mathrm{Pb}$.

\section{DAFTAR PUSTAKA}

Bu SJ, Jin ZG, Liu XX, Yang LR, Cheng ZJ. 2005. Synthesis of $\mathrm{TiO}_{2}$ porous thin films by polyethylene glycol templating and chemistry of the process. Journal of the European Ceramic Society. 25(5): 673-679.

Husna I. 2012. Pengembangan Metode DGT (Diffusive Gradient in Thin Film) dengan Binding Gel Titanium Dioksida untuk Pengukuran Fosfat di Lingkungan. [Skripsi]. Sarjana Departemen Kimia, FMIPA, Unversitas Indonesia.

Mason. 1993. Biology of Freshwater Pollution. New York (US): John Willey and Sons.

Teasdale P, Panther JG, Bennet WW, Welsh DD, Zhao H. 2011. Comparing dissolved reaactive phosphorus measured by DGT with ferryhidrite and titanium dioxide adsorbent: anionic interferences, adsorbent capacity and deployment time. Analytica Chimica Acta. 698(1-2): 20-26

Teasdale P, Panther JG, Bennet WW, Welsh DD, Zhao H. 2010. Titanium dioxide-based DGT technique for in situ measurement of dissolved reactive phosphorus in fresh and marine waters. Environ. Sci. Technol. 44: 9419-9424

Xu D, Chen Y, Ding S, Wang Y. 2013. Diffusive gradient in thin films technique equipped with a mixed binding gel for simultaneous measurements of dissolved reactive phosphorus and dissolve iron. Environ. Sci. Technol. 47, 10477-10484.

Zhang H, Davison W. 2000. Direct in situ measurements of labile inorganic and organically bound metal species in synthetic solutions and natural waters using diffusive gradients in thin films. Anal. Chem. 72: 44474457.

Zhang H, Davison W. 1995. Performance characteristics of diffusion gradient in thin film for the in situ measurement of trace metal in aqueos solution. Anal Chem. 67: 3391-3400.

Zhang H. 2005. Practical Guide for Making Gel and Chelex Gel. Lancester (UK): DGT Research Ltd, Skelmorlie, Quernmore, Lancester LA2 0QJ.

Zhanga H, Davisona W, Gadib R, Kobayashia T. 1998. In situ measurement of dissolved phosphorus in natural waters using DGT. Analytical Chimica Acta. 370(1): 29-38. 